\title{
Oxygen Assisted Trimming Growth of Ultra-High Vertical Graphene Films in a PECVD Process for Superior Energy Storage
}

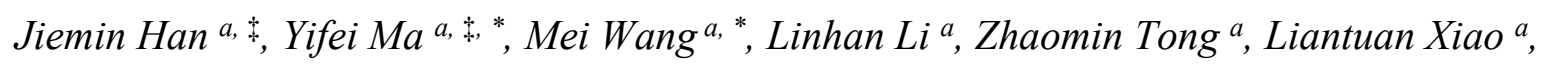
Suotang Jia ${ }^{a}$ and Xuyuan Chen ${ }^{a, b, *}$

${ }^{\text {a }}$ State Key Laboratory of Quantum Optics and Quantum Optics Devices, Institute of Laser Spectroscopy, Collaborative Innovation Center of Extreme Optics, Shanxi University, Taiyuan, 030006, China.

${ }^{\mathrm{b}}$ Faculty of Technology, Natural Sciences and Maritime Sciences, Department of Microsystems, University of Southeast Norway, Borre N-3184, Norway.

Corresponding author. E-mail: mayifei@sxu.edu.cn, wangmei@sxu.edu.cn, xuyuan.chen@usn.no 


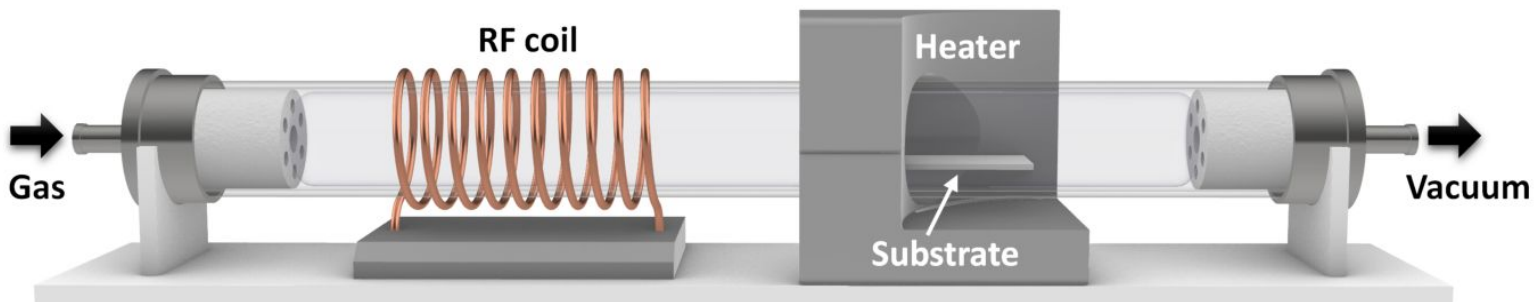

Figure S1. Schematic image of RF-PECVD for producing VGs and UVGs.

Table S1. Experimental conditions of the VGs and UVGs

\begin{tabular}{ccccccccc}
\hline & \multicolumn{5}{c}{ Deposition process } & \multicolumn{5}{c}{ Correction process } \\
Specimen & $\mathrm{H}_{2}$ & $\mathrm{C}_{2} \mathrm{H}_{2}$ & $\mathrm{RF}$ power & Time & $\mathrm{O}_{2}$ & RF power & Time & Repetition \\
& $(\mathrm{sccm})$ & $(\mathrm{sccm})$ & $(\mathrm{W})$ & $(\mathrm{h})$ & $(\mathrm{sccm})$ & $(\mathrm{W})$ & $(\mathrm{min})$ & \\
\hline VG-1h & 2 & 6 & 500 & 1 & - & - & - & - \\
VG-2h & 2 & 6 & 500 & 2 & - & - & - & - \\
VG-6h & 2 & 6 & 500 & 6 & - & - & - & - \\
UVG-2h & 2 & 6 & 500 & 2 & 1 & 200 & 3 & 1 \\
UVG-6h & 2 & 6 & 500 & 6 & 1 & 200 & 15 & 5 \\
UVG-12h & 2 & 6 & 500 & 12 & 1 & 200 & 33 & 11 \\
\hline
\end{tabular}




\section{The details of simulations:}

In the plasma process, the sheath potential may vary from several to hundreds of volts, and the sheath thickness will also vary from micrometer to millimeter ${ }^{1-5}$. Simplified models were used in the COMSOL simulation to focus on the electric field distribution depending on the surface structure of VG. As shown in Figure S2, the geometries of VG and UVG were built according to the SEM images of them, and the properties of graphite were endowed to these models. The plasma sheath near the VG was simplified by the parallel plate electric field with a distance of $3 \mu \mathrm{m}$, an upper voltage of $0 \mathrm{~V}$ and a lower voltage of $-1 \mathrm{~V}$.

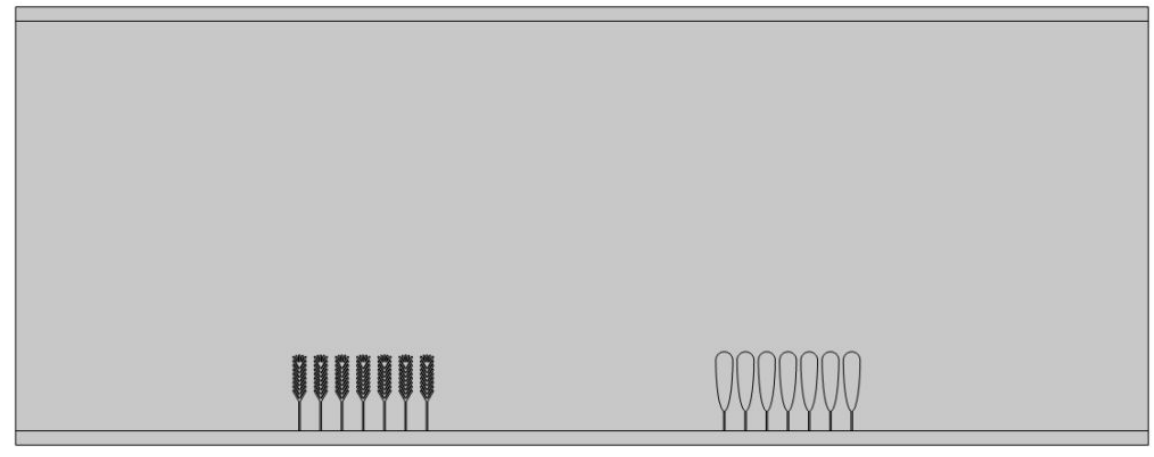

Figure S2. Models in COMSOL simulation.

\section{References:}

(1) Panagopoulos, T.; Economou, D. J. Plasma Sheath Model and Ion Energy Distribution for All Radio Frequencies. J. Appl. Phys 1999, 85 (7), 3435-3443.

(2) Han, H.-S.; Lee, H.-C.; Oh, S.-J.; Chung, C.-W. Measurement of Sheath Thickness at a Floating Potential. Physics of Plasmas 2014, 21 (2), 023512.

(3) Martin, P.; Maass-Artigas, F.; Cortés-Vega, L. Analytic Approximate for the Plasma Sheath Potential. Journal of Physics: Conference Series 2016, 720, 012040.

(4) Kos, L.; Jelić, N.; Gyergyek, T.; Kuhn, S.; TskhakayaSr., D. D. Modeling and Simulations of Plasma and Sheath Edges in Warm-ion Collision-free Discharges. AIP Advances 2018, 8 (10), 105311.

(5) Faudot, E.; Ledig, J.; Moritz, J.; Heuraux, S.; Lemoine, N.; Devaux, S. Experimental Measurements of the RF Sheath Thickness with a Cylindrical Langmuir Probe. Physics of Plasmas 2019, 26 (8), 083503. 


\section{Calculations:}

The electrochemical data of UVG-12h from Figure S8f at $0.1 \mathrm{~mA} \mathrm{~cm}^{-2}$ is chosen as an example to explain how to calculate the final result.

The voltage drop upon discharging $(\Delta V)$ of galvanostatic charge/discharge (GCD) measurement is $0.99814 \mathrm{~V}$. The current density is $0.1 \mathrm{~mA} \mathrm{~cm}^{-2}$, which is the ratio of charge and discharge current $(I)$ to the area of the working electrode $(A)$. The discharge time $(t)$ of the UVG-12h at $0.1 \mathrm{~mA} \mathrm{~cm}^{-2}$ is $2409.03723 \mathrm{~s}$.

Then, the specific areal capacitance is calculated according to the following equation:

$$
C_{S}=\frac{I \times t}{A \times \Delta V}=0.1 \times \frac{2409.03723}{0.99814} \approx 241.35\left(\mathrm{mF} \mathrm{cm}^{-2}\right)
$$

The thickness $(h)$ of the UVG-12h films is $80 \mu \mathrm{m}$ obtained from SEM image. The specific volumetric capacitances is calculated according to the following equation:

$$
C_{V}=\frac{C_{S}}{h}=\frac{241.35}{80} \approx 30.17\left(\mathrm{mF} \mathrm{cm}^{-3}\right)
$$

The areal energy and power density are calculated as follows:

$$
\begin{gathered}
\left.E=\frac{1}{2} \times C \times \frac{(\Delta V)^{2}}{3600}=\frac{1}{2} \times 241.35 \times \frac{(0.99814)^{2}}{3600} \approx 33.396(\mu \mathrm{Wh} \mathrm{cm})^{-2}\right) \\
P=3600 \times \frac{E}{t}=3600 \times \frac{33.396}{2409.03723} \approx 0.05\left(\mathrm{~mW} \mathrm{~cm}^{-2}\right)
\end{gathered}
$$



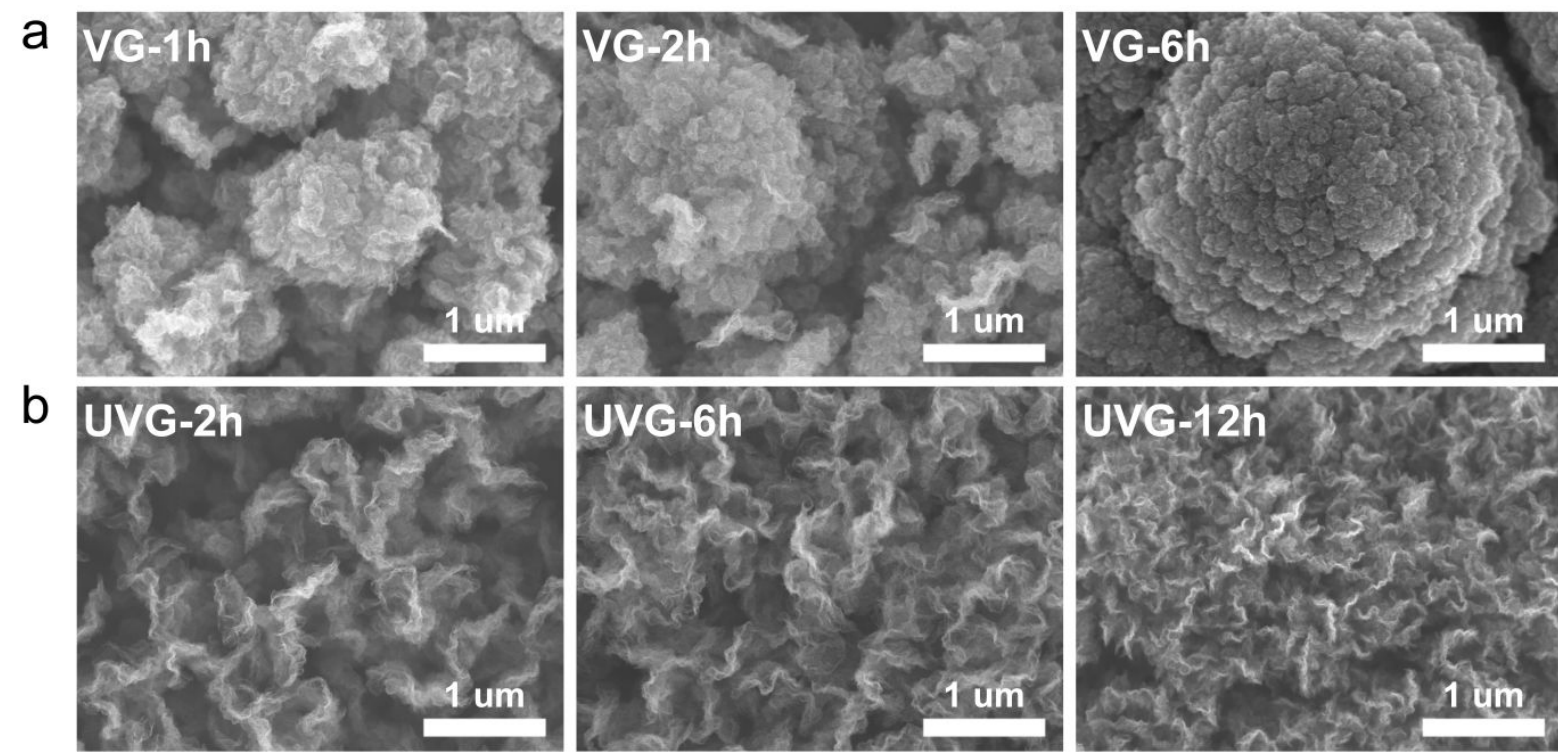

Figure S3. Top-view SEM images of VGs and UVGs.

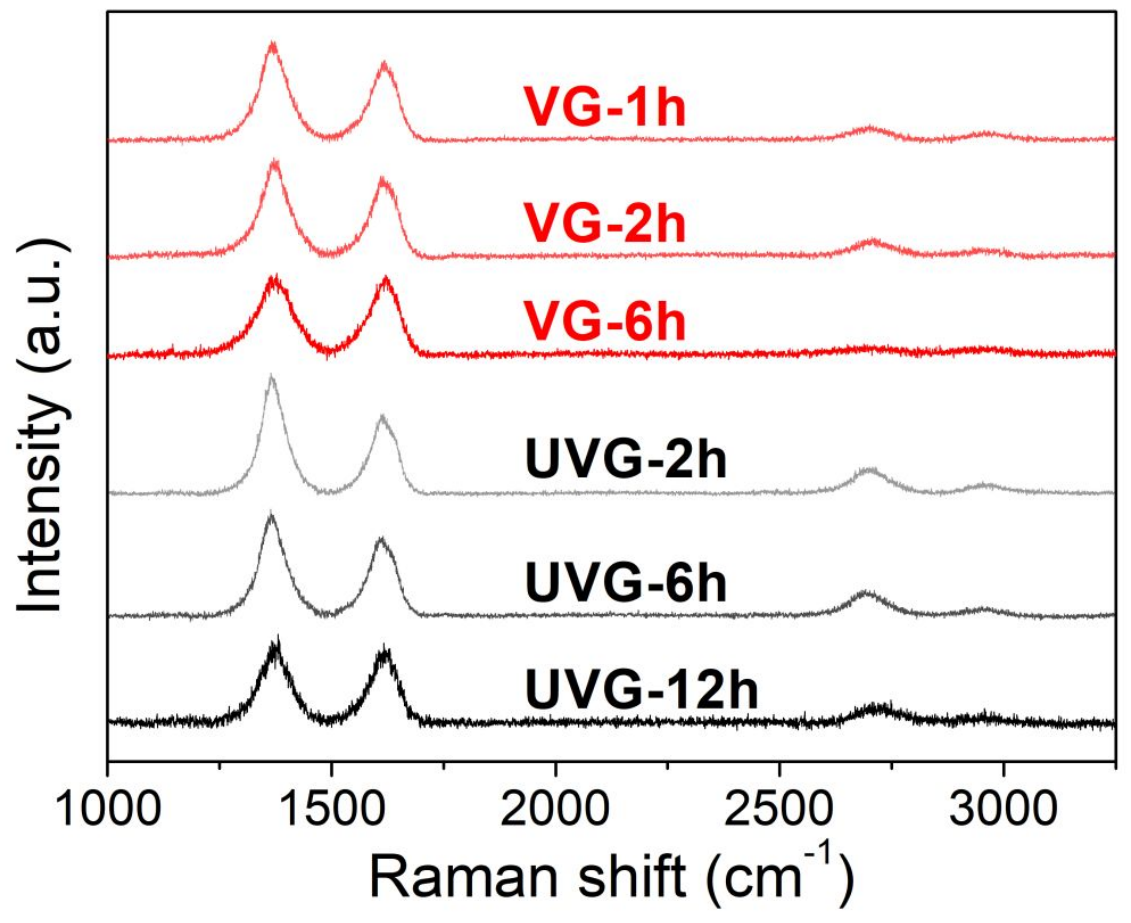

Figure S4. The Raman spectra of VGs. 


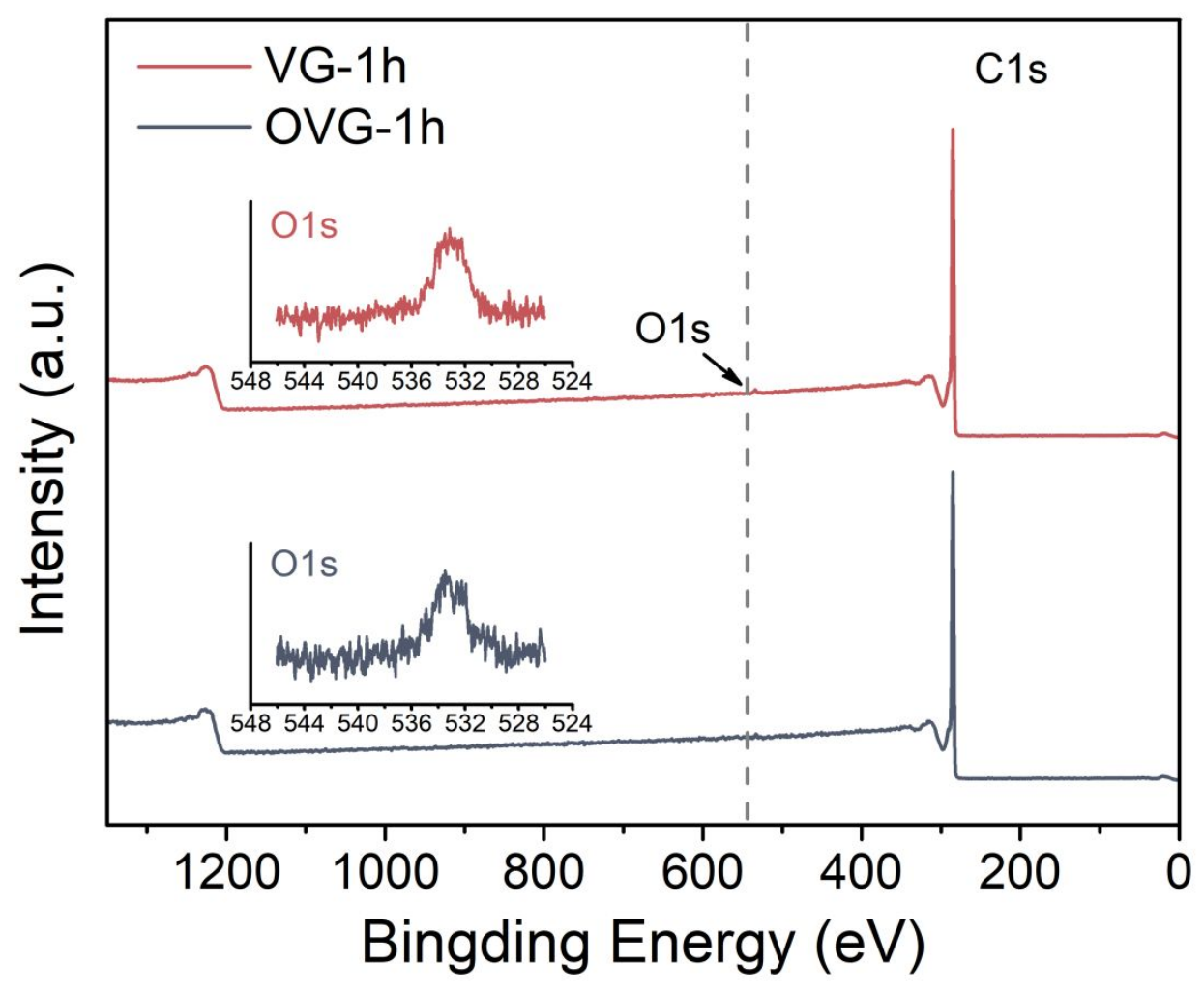

Figure S5. XPS survey of VG before (red line) and after (black line) trimming by oxygenassisted-trimming. 
Table S2. XPS Peak of C 1s and O 1s.

\begin{tabular}{ccccc}
\hline Sample & Name & Peak & FWHM (eV) & Atomic \\
\hline $\begin{array}{c}\text { VG after oxygen- } \\
\text { assisted-trimming } \\
\text { (OVG-1h) }\end{array}$ & C 1s & 284.06 & 2.83 & $98.51 \%$ \\
\cline { 2 - 5 } & O 1s & 531.95 & 3.26 & $1.49 \%$ \\
\hline \begin{tabular}{c} 
VG before oxygen- \\
assisted-trimming \\
\cline { 2 - 5 }$($ VG-1h)
\end{tabular} & C 1s & 284.80 & 1.07 & $99.33 \%$ \\
\hline
\end{tabular}

Table S3. The C 1s photoelectron analysis of VG-1h and OVG-1h.

\begin{tabular}{cccc}
\hline \multirow{2}{*}{ Peak } & Specimen & FWHM (eV) & Area (\%) \\
\hline C-C & VG-1h & 0.87 & 76.17 \\
\cline { 2 - 4 } & OVG-1h & 0.85 & 73.46 \\
\hline C-H & VG-1h & 1.03 & 11.35 \\
\cline { 2 - 4 } & OVG-1h & 0.99 & 12.97 \\
\hline C-O & VG-1h & 2.22 & 6.01 \\
\cline { 2 - 4 } & OVG-1h & 2.42 & 6.04 \\
\hline $\mathrm{C}=\mathrm{O}$ & VG-1h & 1.82 & 6.47 \\
\cline { 2 - 4 } & OVG-1h & 2.23 & 7.53 \\
\hline
\end{tabular}



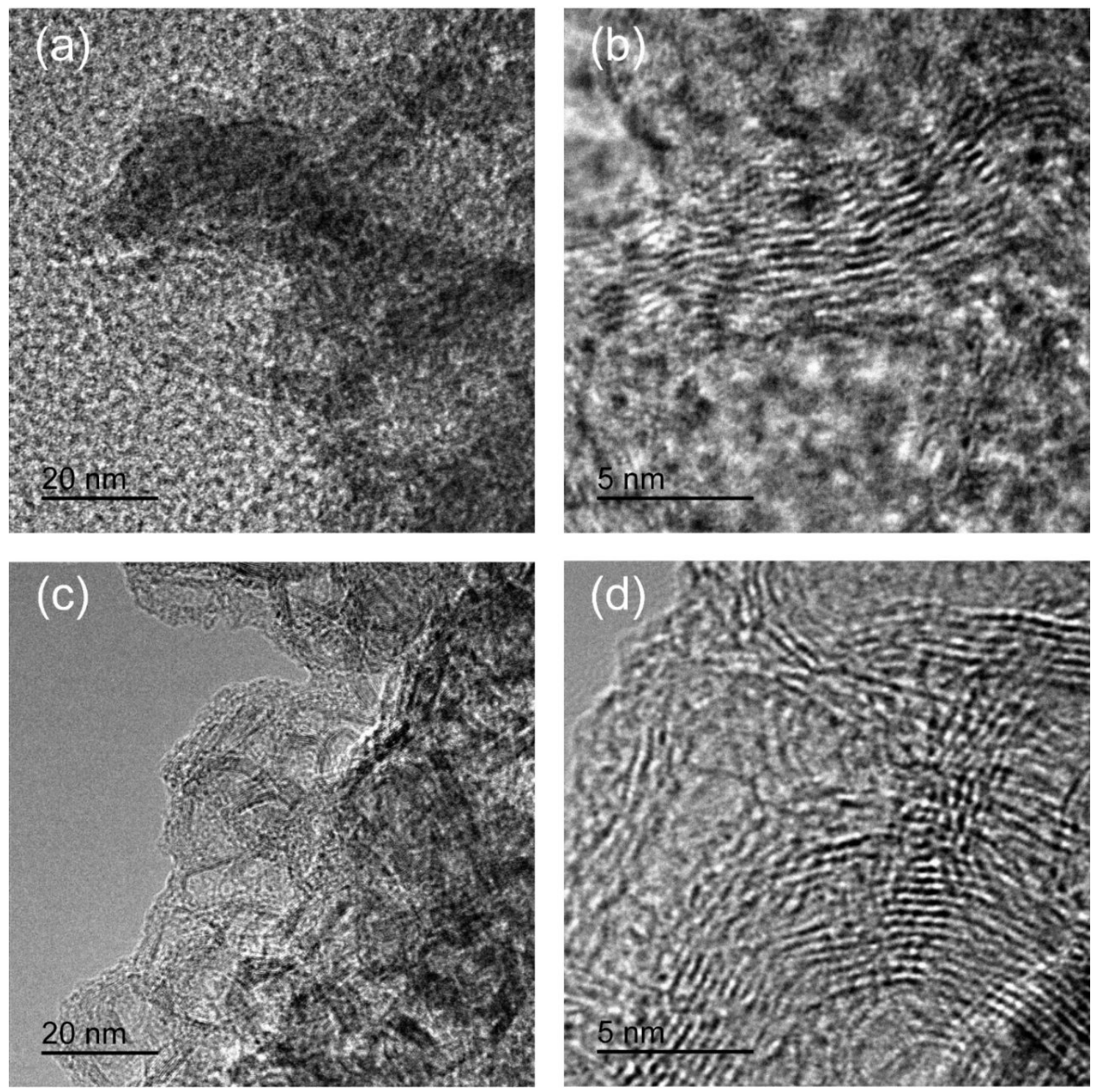

Figure S6. TEM images of the edges of VG (a-b) and UVG (c-d).
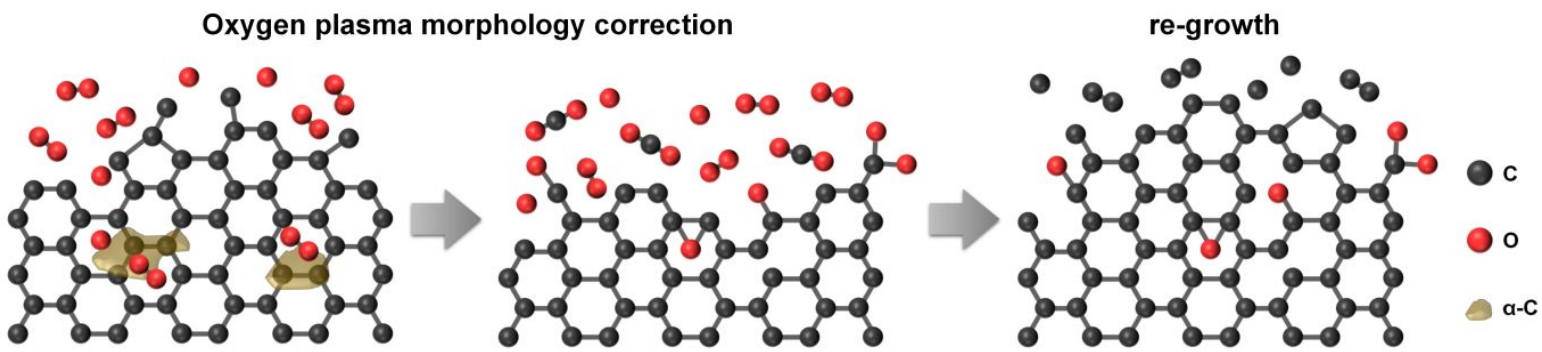

Figure S7. Schematics showing the oxygen plasma morphology correction and re-growth mechanisms. 

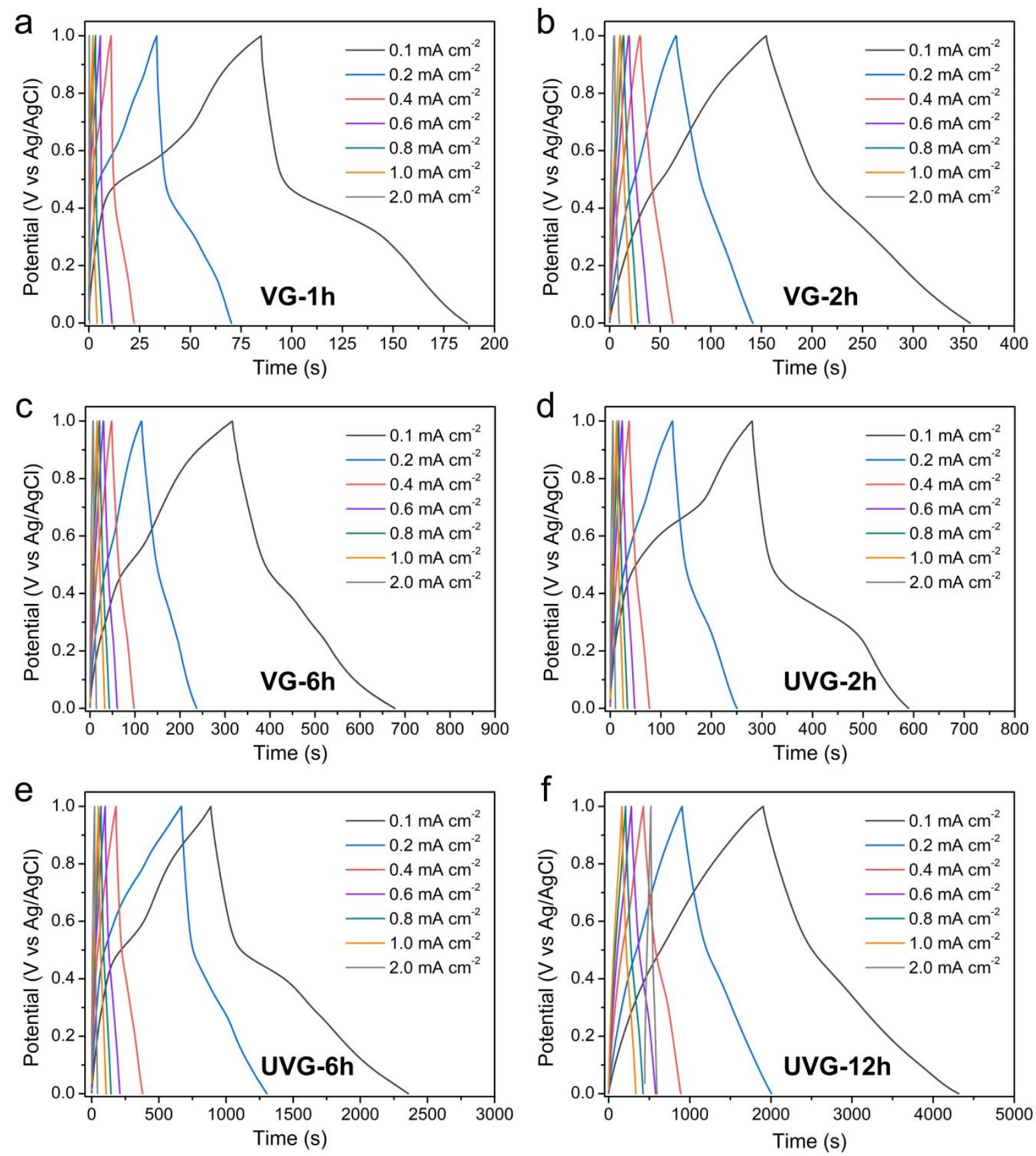

Figure S8. GCD measurement of VG and UVG at various current densities from 0.1 to 2.0 mA cm c $^{-2}$. (a) VG-1h, (b) VG-2h, (c) VG-6h, (d) UVG-2h, (e) UVG-6h, and (f) UVG-12h. 

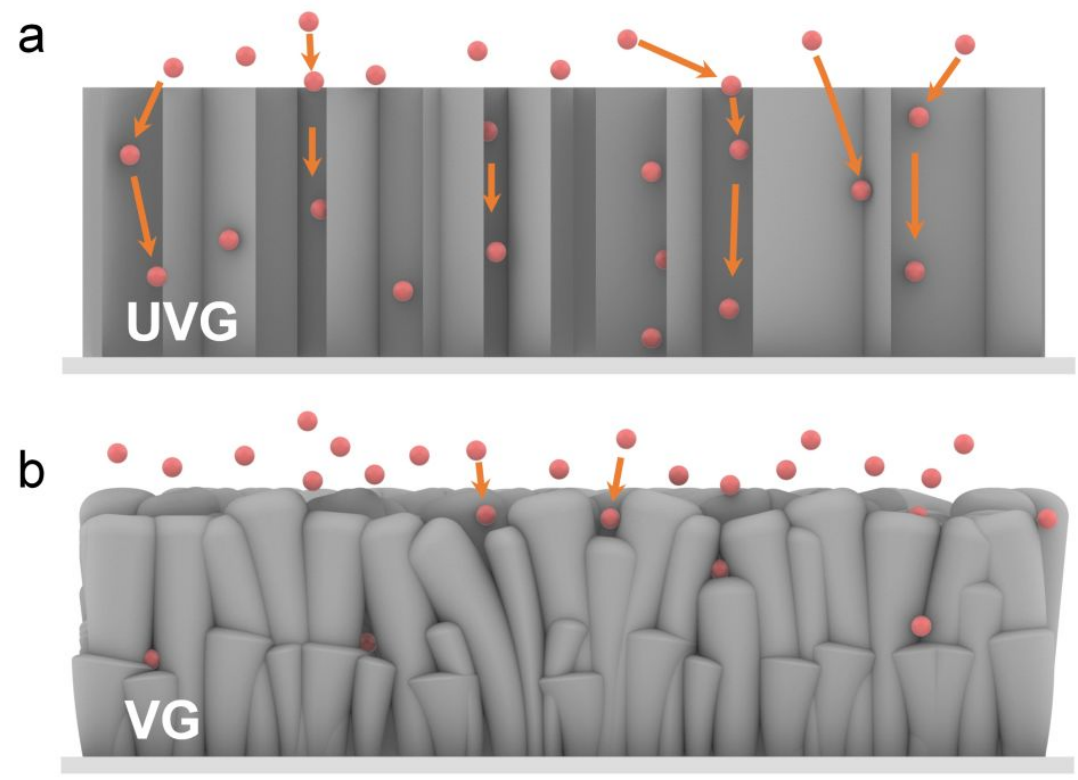

Ion $\longleftarrow$ Ions transportation direction

Figure S9. Schematic images of ions transportation in UVG (a) and VG (b).

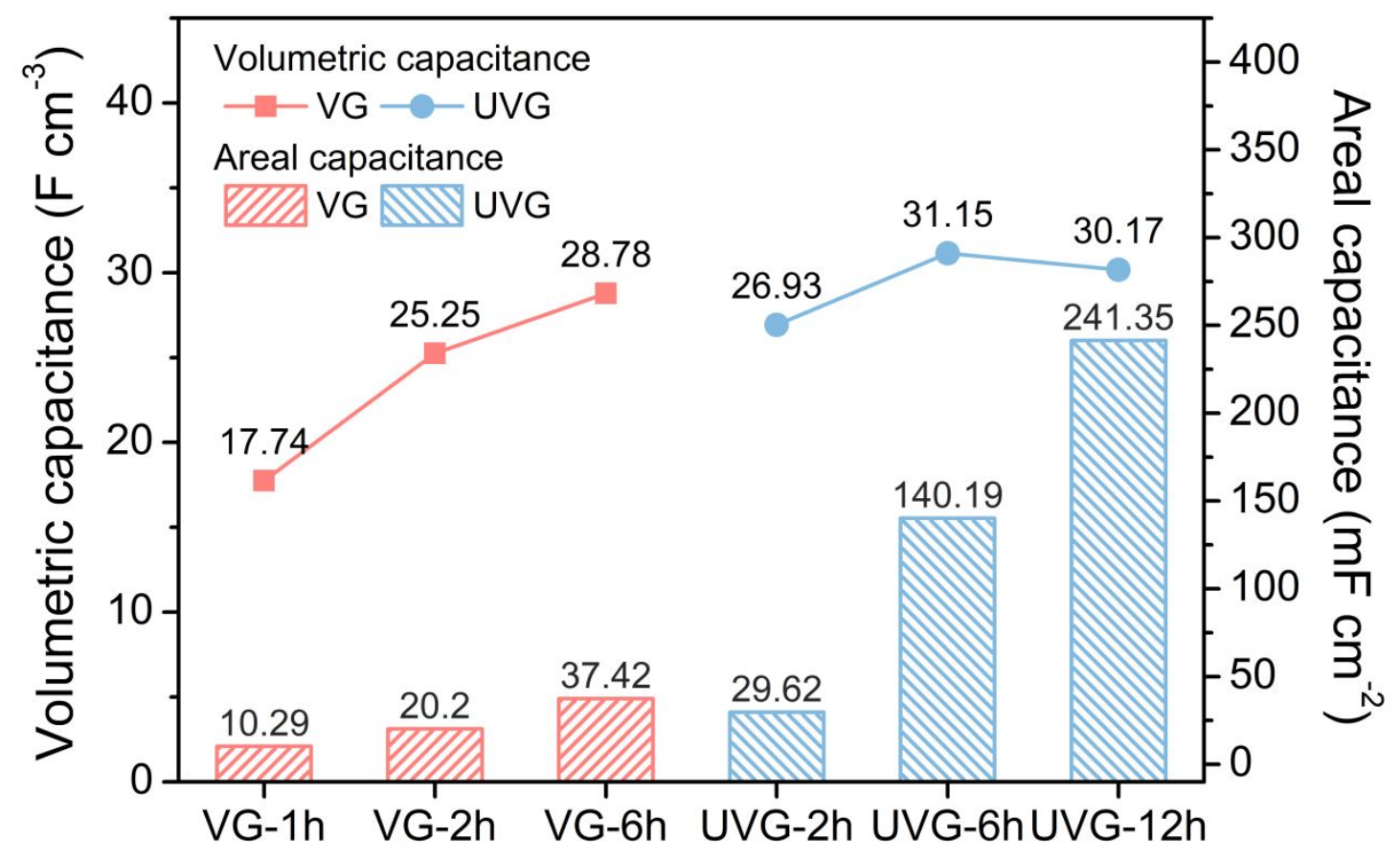

Figure S10. Volumetric and areal capacitance of VGs and UVGs at $0.1 \mathrm{~mA} \mathrm{~cm}{ }^{-2}$. 

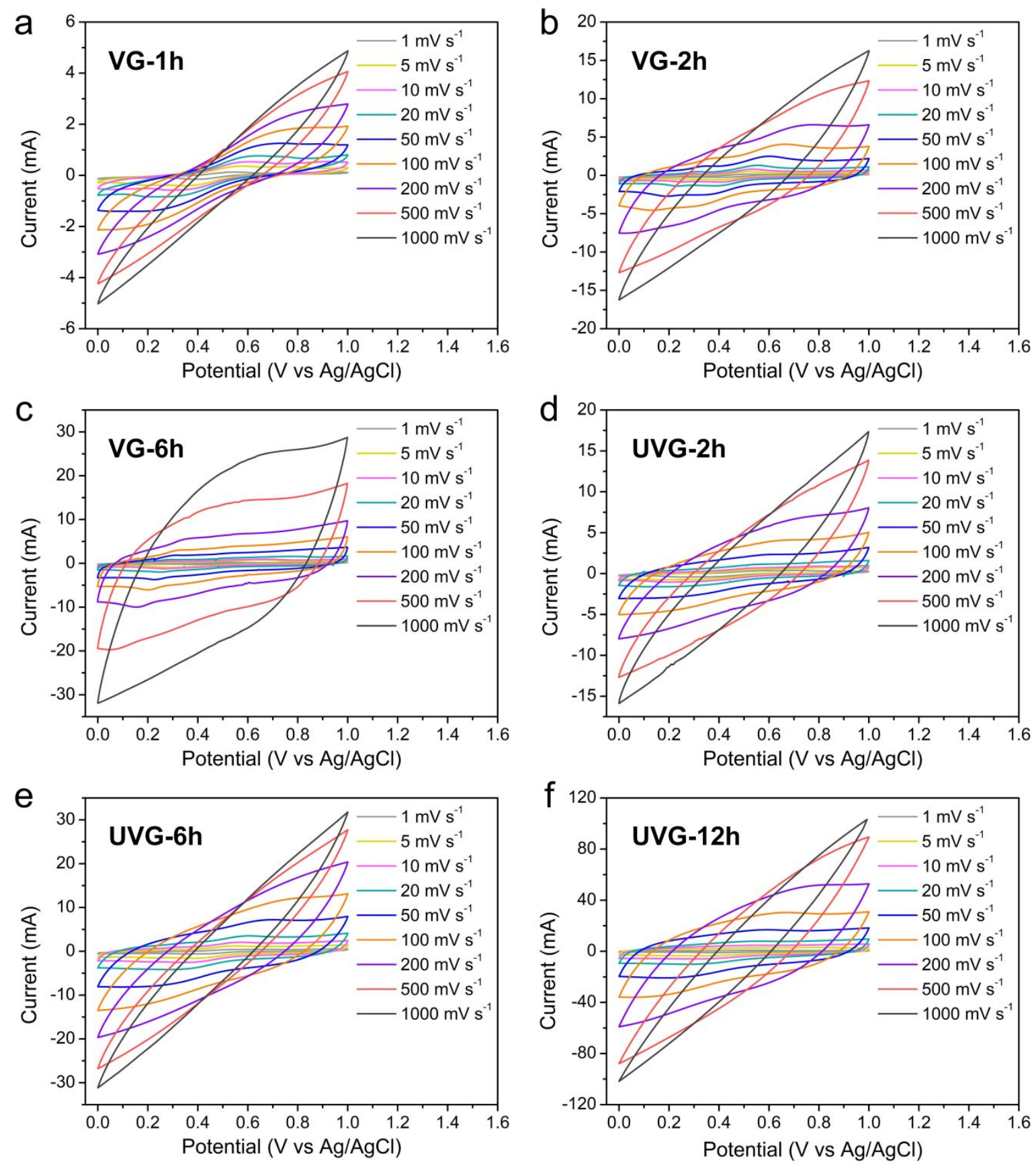

Figure S11. CV measurement of VG and UVG at various scan rates from 1 to $1000 \mathrm{mV} \mathrm{s}^{-1}$.

(a) VG-1h, (b) VG-2h, (c) VG-6h, (d) UVG-2h, (e) UVG-6h, and (f) UVG-12h. 
Table S4. Comparison of areal capacitances of VG with reported VGs.

\begin{tabular}{|c|c|c|c|}
\hline Method & $\begin{array}{l}\text { VG height } \\
(\mu \mathrm{m})\end{array}$ & $\begin{array}{l}\text { Areal capacitance } \\
\left(\mathrm{mF} \mathrm{cm}^{-2}\right)\end{array}$ & Ref. \\
\hline RF-PECVD / Pulsed Laser Ablation & 0.50 & 4.30 & 6 \\
\hline Electron Cyclotron Resonance CVD & 0.51 & 1.65 & 7 \\
\hline PECVD / N-doped & 2.80 & 2.70 & 8 \\
\hline ECR-PECVD & $\sim 0.10-1.00$ & 0.20 & 9 \\
\hline PECVD & 6.40 & 2.30 & 10 \\
\hline DC-CVD & - & $0.80-1.00$ & 11 \\
\hline RF-PECVD & $\sim 0.10$ & 0.70 & 12 \\
\hline RF-PECVD & 80.00 & 241.35 & This work \\
\hline
\end{tabular}

References

(6) Guerra, A.; Achour, A.; Vizireanu, S.; Dinescu, G.; Messaci, S.; Hadjersi, T.; Boukherroub, R.; Coffinier, Y.; Pireaux, J.-J. ZnO/Carbon Nanowalls Shell/Core Nanostructures as Electrodes for Supercapacitors. Applied Surface Science 2019, 481, 926-932.

(7) Sahoo, G.; Polaki, S. R.; Ghosh, S.; Krishna, N. G.; Kamruddin, M. Temporal-Stability of Plasma Functionalized Vertical Graphene Electrodes for Charge Storage. J Power Sources 2018, 401, 37-48.

(8) Wang, M.; Ma, Y. Nitrogen-doped Graphene Forests as Electrodes for High-Performance Wearable Supercapacitors. Electrochimica Acta 2017, 250, 320-326.

(9) Ghosh, S.; Mathews, T.; Gupta, B.; Das, A.; Gopala Krishna, N.; Kamruddin, M. Supercapacitive Vertical Graphene Nanosheets in Aqueous Electrolytes. Nano-Structures \& Nano-Objects 2017, 10, 42-50.

(10) Ma, Y.; Wang, M.; Kim, N.; Suhr, J.; Chae, H. A Flexible Supercapacitor Based on Vertically Oriented 'Graphene Forest' Electrodes. J. Mater. Chem. A 2015, 3 (43), $21875-$ 21881.

(11) Komarova, N. y. S.; Krivenko, A. G.; Stenina, E. V.; Sviridova, L. N.; Mironovich, K. V.; Shulga, Y. M.; Krivchenko, V. A. Enhancement of the Carbon Nanowall Film Capacitance. Electron Transfer Kinetics on Functionalized Surfaces. Langmuir 2015, 31 (25), 7129-7137.

(12) Qi, J. L.; Wang, X.; Lin, J. H.; Zhang, F.; Feng, J. C.; Fei, W.-D. A High-Performance Supercapacitor of Vertically-Oriented Few-Layered Graphene with High-density Defects. Nanoscale 2015, 7 (8), 3675-3682. 


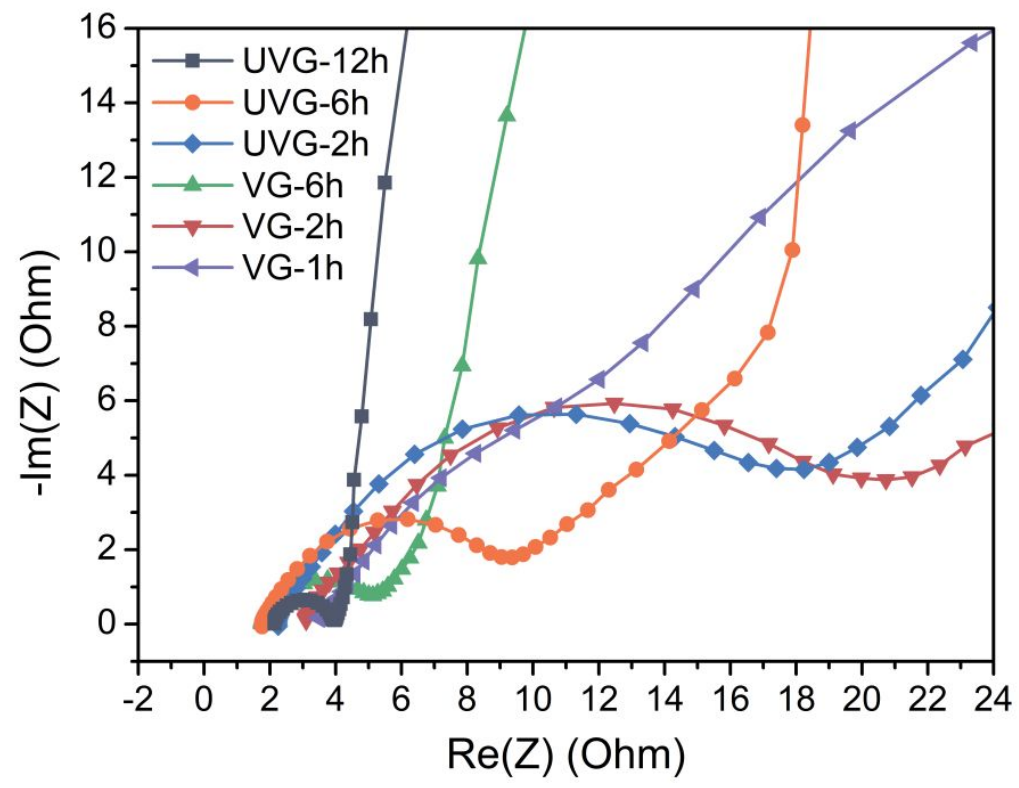

Figure S12. Detailed Nyquist plot of the high-frequency region based on the VGs and UVGs.
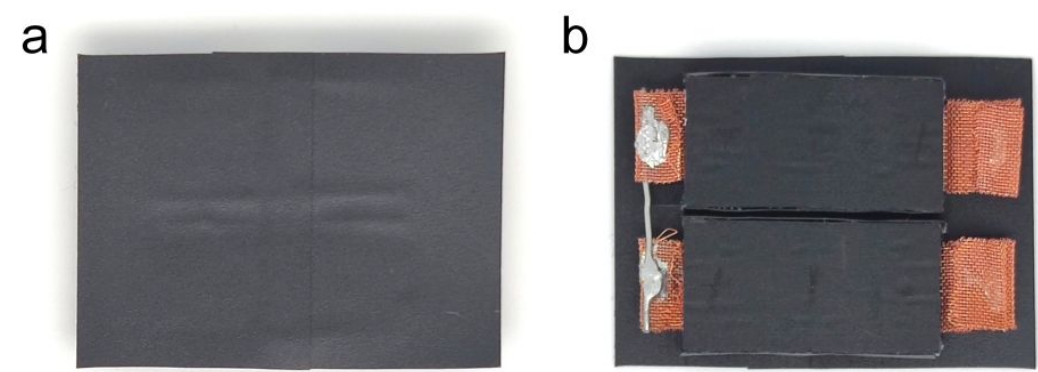

Figure S13. The UVG supercapacitor unit is composed of two $1.7 \mathrm{~cm} \times 0.8 \mathrm{~cm} \mathrm{UVG-12h}$ based supercapacitors in series, which is wrapped with black tape. 